\title{
Corrosion of the component phases presents in high copper dental amalgams. Application of electrochemical impedance spectroscopy and electrochemical noise analysis
}

\author{
Heloísa A. Acciari a, Antonio C. Guastaldi ${ }^{a, *}$, \\ Christopher M.A. Brett ${ }^{b}$ \\ ${ }^{a}$ Departamento de Físico-Química, Instituto de Química de Araraquara-UNESP, \\ C.P. 355, Araraquara-SP, Brazil \\ ${ }^{\mathrm{b}}$ Departamento de Química, Universidade de Coimbra, 3004-535 Coimbra, Portugal
}

Available online 13 August 2004

\begin{abstract}
The corrosion resistance of three of the constituent phases in high copper dental amalgams has been investigated by electrochemical methods in $0.9 \% \mathrm{NaCl}$ solution. Polarization curves show corrosion potentials most positive for $\gamma_{1}-\mathrm{Ag}_{2} \mathrm{Hg}_{3}$, followed by $\mathrm{Ag}-\mathrm{Cu}$, and $\gamma-\mathrm{Ag}_{3} \mathrm{Sn}$ in agreement with the order of corrosion resistance deduced from the corrosion currents. Complex plane impedance plots at the open circuit potential showed distorted semicircles with diffusional components at low frequency for $\mathrm{Ag}-\mathrm{Hg}$ and $\mathrm{Ag}-\mathrm{Cu}$, while for $\gamma-\mathrm{Ag}_{3} \mathrm{Sn}$ a layer of corrosion products is formed, partially or completely covering the surface of the electrode. Impedance and noise spectra have been compared in the frequency domain, and show good agreement.
\end{abstract}

(C) 2004 Elsevier Ltd. All rights reserved.

Keywords: A. Dental amalgams; A. Amalgam phases; B. Electrochemical impedance spectroscopy (EIS); B. Electrochemical noise analysis; C. Chloride corrosion

\footnotetext{
* Corresponding author. Tel.: +55 16 2016655; fax: +55 162227932 .

E-mail address: guastald@iq.unesp.br (A.C. Guastaldi).
} 


\section{Introduction}

Dental amalgam has been used as a restorative material for the replacement of the decayed tooth structure for more than 150 years [1]. Nevertheless, in recent years investigations of its corrosion and wear resistance have become of great interest owing to concerns deriving from toxic effects arising from corrosion products in the oral cavity, particularly mercury and its compounds, as well as from amalgam particles. The more recent high copper dental amalgams show advantages in reducing toxicity due to mercury release.

Amalgam is a metallic alloy formed by reaction between mercury and an original alloy in powder form containing silver, tin, copper, zinc, etc., and with a very complex metallurgical structure [1]. During amalgamation the mercury diffuses into the amalgam particles and dissolves them. The solubility of mercury in silver, tin and copper differ considerably. One mg of mercury will dissolve in copper at the same temperature as 10 and $170 \mathrm{mg}$ of mercury will dissolve in silver and tin, respectively. Therefore particles composed mainly of silver and tin will dissolve almost all the mercury, and very little mercury will be dissolved by the silver-copper particles [1]

The mercury dissolved in the silver-tin particles forms $\gamma_{1}-\mathrm{Ag}_{2} \mathrm{Hg}_{3}$ and $\gamma_{2}-\mathrm{Sn}_{7} \mathrm{Hg}$ phases, leaving some unreacted silver-tin particles. In a relatively short time the newly formed $\gamma_{2}-\mathrm{Sn}_{7} \mathrm{Hg}$ phase around the silver-tin particles reacts with silvercopper particles forming the $\eta^{\prime}-\mathrm{Cu}_{6} \mathrm{Sn}_{5}$ phase of the copper-tin system together with some $\gamma_{1}-\mathrm{Ag}_{2} \mathrm{Hg}_{3}$ phase around the silver-copper particles.

The amalgamation reactions may be summarized as [1]:

$$
\gamma-\mathrm{Ag}_{3} \mathrm{Sn}+\mathrm{Ag}-\mathrm{Cu}+\mathrm{Hg} \rightarrow \gamma_{1}-\mathrm{Ag}_{2} \mathrm{Hg}_{3}+\gamma_{2}-\mathrm{Sn}_{7} \mathrm{Hg}+\gamma-\mathrm{Ag}_{3} \mathrm{Sn}+\mathrm{Ag}-\mathrm{Cu}
$$

followed by

$$
\gamma_{2}-\mathrm{Sn}_{7} \mathrm{Hg}+\mathrm{Ag}-\mathrm{Cu} \rightarrow \eta^{\prime}-\mathrm{Cu}_{6} \mathrm{Sn}_{5}+\gamma_{1}-\mathrm{Ag}_{2} \mathrm{Hg}_{3}
$$

A complex metallurgical structure is obtained, containing up to six phases, as can be seen in the micrograph of Fig. 1 for the high copper amalgam Dispersalloy ${ }^{\circledR}$, each of which has a different corrosion potential. The large dark circular areas represent the $\mathrm{Ag}-\mathrm{Cu}$ eutectic, in dark grey are $\mathrm{Ag}-\mathrm{Sn} \gamma$-phases of irregular form and different sizes, all included in a matrix of $\gamma_{1}-\mathrm{Ag}_{2} \mathrm{Hg}_{3}$ in light grey.

Thus, the corrosion of dental amalgam is a complex process, which involves contributions from each of the phases present as well as from intergranular corrosion. It is thus of interest to investigate the corrosion of the individual phases present.

During the last 10 years, many papers have been published on the corrosion of dental amalgam, the recording of polarization curves being one of the most widely used electrochemical methods for this kind of study [2-4]. More information can be obtained by application of non-stationary techniques, e.g. electrochemical impedance to study the corrosion phenomena [4-6] and references therein. Electrochemical impedance is a powerful tool in the study of the corrosion behavior of different kinds of metals and alloys.

In this work, the corrosion resistance of three of the constituent phases has been investigated, mainly using electrochemical impedance spectroscopy (EIS) and 


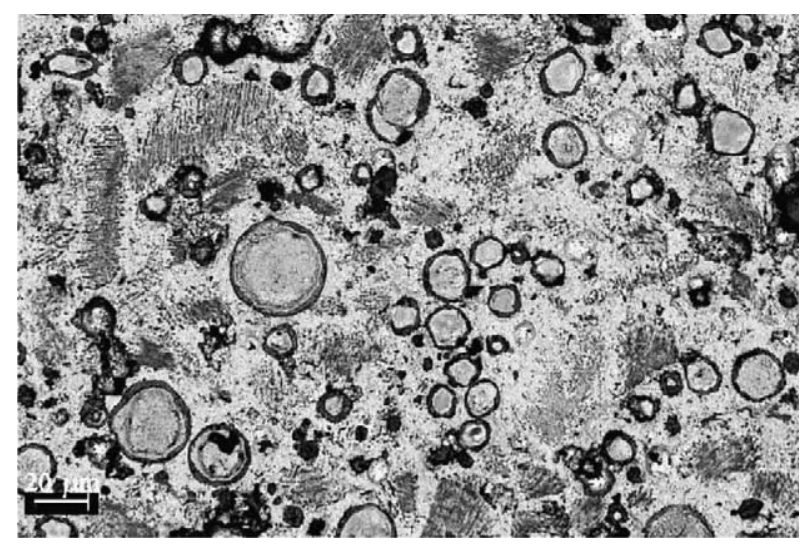

Fig. 1. Scanning electron micrograph, using backscattered electrons, of Dispersalloy dental amalgam, showing the complex multiphase structure.

electrochemical noise analysis (ENA). These phases were $\gamma_{1}-\mathrm{Ag}_{2} \mathrm{Hg}_{3}$ (the matrix phase in the microstructure), $\gamma-\mathrm{Ag}_{3} \mathrm{Sn}$ (the second most prominent phase) and $\mathrm{Ag}-\mathrm{Cu}$-eutectic $(72 \% \mathrm{Ag}, 28 \% \mathrm{Cu})$ which is a component of the more modern powder alloys.

Electrochemical measurements were carried out in $0.9 \%$ aqueous sodium chloride, an electrolyte with similarities to physiological serum, in order to simulate the aggressivity of the oral cavity.

\section{Experimental}

The $\mathrm{Ag}-\mathrm{Hg}$ alloy was made in the correct stoichiometric proportions, taking into account the phase diagrams, by mechanical amalgamation and moulding under high pressure following the criteria adopted by the American Dental Association, Specification No. 1 [7]. The $\mathrm{Ag}-\mathrm{Sn}$ and $\mathrm{Ag}-\mathrm{Cu}$ alloys were prepared by heating the components until they were completely melted, and then the melt was poured into a mould to form an ingot. After the ingot was completely cooled, it was heated at $180{ }^{\circ} \mathrm{C}$ for one week $(\mathrm{Ag}-\mathrm{Sn})$ and at $770{ }^{\circ} \mathrm{C}$ for one week $(\mathrm{Ag}-\mathrm{Cu})$ and cooled slowly. The samples were examined by scanning electron microscopy and X-ray diffraction.

Electrodes were made from samples by embedding in resin leaving one face exposed, area $\sim 0.3 \mathrm{~cm}^{2}$, polishing with 600 and 1000 grade emery papers, rinsed with distilled water and dried in air.

Electrochemical experiments were performed in a three-electrode cell containing $0.9 \% \mathrm{NaCl}$ solution. The counter electrode was Pt foil and the reference electrode was a saturated calomel electrode (SCE). Solutions were prepared using analytical grade reagent and Millipore Milli-Q water (resistivity $>18 \mathrm{M} \Omega \mathrm{cm}$ ), and were not deaerated. Experiments were carried out at room temperature $\left(25 \pm 1{ }^{\circ} \mathrm{C}\right)$. 
Impedance measurements were made at the open circuit potential after 24, 48 and $72 \mathrm{~h}$ immersion, using a Solartron 1255 Frequency Response Analyser coupled to a Solartron 1287 Electrochemical Interface (Solartron Analytical, Farnborough, UK) using a $10 \mathrm{mV}$ rms perturbation in the frequency range $100 \mathrm{kHz}$ to $0.1 \mathrm{~Hz}$, five points per frequency decade, and controlled by ZPlot software with analysis by ZView software (Scribner Associates, Charlottesville, USA).

Electrochemical noise tests consisted of recording simultaneously the potential and current fluctuations at a sampling rate of 2 points per second for a period of $1024 \mathrm{~s}$ using the Solatron 1287 Electrochemical Interface potentiostat. These tests require a different configuration of the cell and two identical samples with identical geometric areas were exposed parallel to each other in $0.9 \% \mathrm{NaCl}$ solution. An SCE reference electrode was placed midway between the two test electrodes. Data obtained were transformed into the frequency domain using a fast Fourier transform (FFT) algorithm. Simultaneous sampling of potential and current noise makes it possible to reveal the relationship between potential and current in the frequency domain.

\section{Results and discussion}

\subsection{Polarization curves}

Potentiodynamic polarization curves and the relative rates of corrosion are shown in Fig. 2 recorded after 10 min immersion.

The plot recorded for $\gamma_{1}-\mathrm{Ag}_{2} \mathrm{Hg}_{3}$ shows a passive zone between the potentials -0.1 and $+0.1 \mathrm{~V}$ vs. SCE, probably due to formation of $\mathrm{AgCl}$ and $\mathrm{Hg}_{2} \mathrm{Cl}_{2}$, but

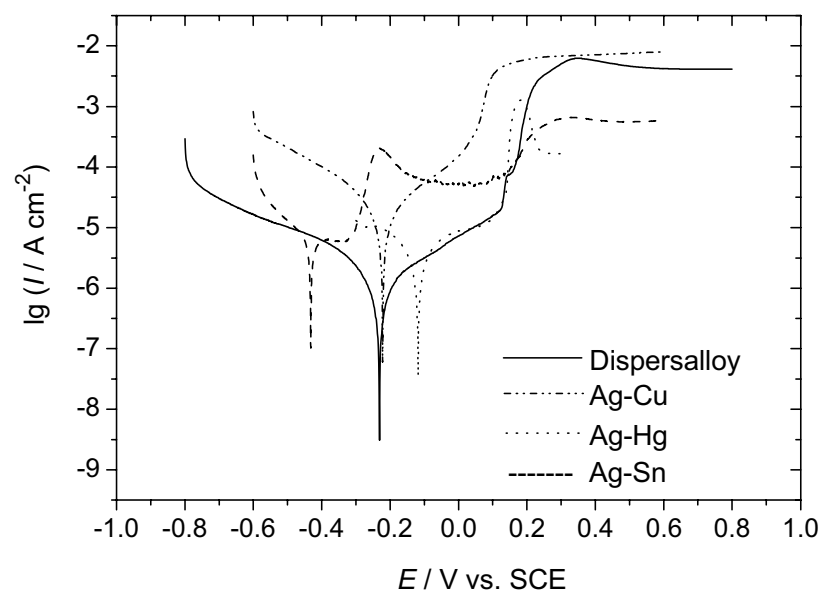

Fig. 2. Potentiodynamic polarization curves, scan rate $2.5 \mathrm{~m} \mathrm{~V} \mathrm{~s}^{-1}$, after $10 \mathrm{~min}$ immersion in $0.9 \% \mathrm{NaCl}$ solution. 
the anodic current increased at approximately $0.15 \mathrm{~V}$, because $\mathrm{AgCl}$ and $\mathrm{Hg}_{2} \mathrm{Cl}_{2}$ are discontinuous through the surface and oxidation to $\mathrm{Hg}$ (II) can occur.

According to the $\mathrm{Ag}-\mathrm{Cu}$ potentiodynamic behaviour after $10 \mathrm{~min}$ immersion, a zone of constant current density around $10^{-2} \mathrm{Acm}^{-2}$ from -0.05 to $0.05 \mathrm{~V}$ is observed, attributable to formation of copper oxide. In the literature, there is evidence that $\mathrm{Cu}_{2} \mathrm{O}$ grows on pure copper as a primary corrosion product in aerated sodium chloride solution, in an intermediate reaction to form $\mathrm{CuCl}_{2}$. This film is considerably porous, which leads to a relatively ineffective protection of the metal; due to the high electronic conductivity of $\mathrm{Cu}_{2} \mathrm{O}$ and to copper ion diffusion through the pores, the current increases with anodic polarization [8]. $\gamma-\mathrm{Ag}_{3} \mathrm{Sn}$ shows a passivation process beginning at $-0.2 \mathrm{~V}$ and extends up to $\sim 0.1 \mathrm{~V}$ vs. SCE when the layer begins to break down. Data for potentiodynamic polarization of $\gamma-\mathrm{Ag}_{3} \mathrm{Sn}$ [5] show oscillations in current and suggest the formation and dissolution of the oxide layer, probably by the formation of oxy-chloro complexes. In particular, after a short immersion time, there is also evidence of passivation beginning at $-0.4 \mathrm{~V}$ and up to $-0.3 \mathrm{~V}$, maybe due to the formation of $\mathrm{Sn}$ (II) oxide, which disappears at -0.3 $\mathrm{V}$ when the current rises again.

The polarization curve of Dispersalloy is also shown for comparative purposes. There is evidence of passivation from -0.18 up to $-0.8 \mathrm{~V}$ vs. SCE. A low passive current density, 4-5 $\mu \mathrm{Acm}^{-2}$, typical of a passive system, is observed at relatively low potentials, but passive film breakdown is seen above $+0.25 \mathrm{~V}$. The profile seems to reflect mainly that of the $\gamma_{1}-\mathrm{Ag}_{2} \mathrm{Hg}_{3}$ and $\mathrm{Ag}-\mathrm{Cu}$ phases.

\subsection{Electrochemical impedance spectroscopy}

Since dental amalgams are multiphase materials, representation of the electrochemical behaviour for corroding dental amalgam phases using simple equivalent electrical circuits cannot be expected [6]. This may often be ascribed to the imperfect cell geometry resulting in a non-uniform current distribution, since the corrosion process is localized on defects in the non-homogeneous surface [9]. The inclusion of a constant phase element (CPE) in the equivalent circuit provides a parameter $\alpha$, corresponding to the degree of distortion of the spectrum or to surface roughness. The decrease of $\alpha$ as a function of time can be explained by an increasing number of pores and surface roughness [6].

Typical impedance spectra are shown in Fig. 3 for each of the three phases, showing both the experimental points and fitted curve.

\subsubsection{The silver-mercury phase}

The frequency response of $\gamma_{1}-\mathrm{Ag}_{2} \mathrm{Hg}_{3}$ after 24,48 and $72 \mathrm{~h}$ immersion at open circuit is shown in Fig. 3a in complex plane format, with the fitted curve calculated using an equivalent circuit composed of the cell resistance, $R_{\Omega}$, and the capacitance of the interface, represented by a constant phase element $\mathrm{CPE}_{1}$ which models a nonideal capacitance according to $\mathrm{CPE}=(\mathrm{Ci} \omega)^{\alpha}$, in parallel with a polarization resistance, $R_{p 1}$. Table 1 lists the values of the circuit elements deduced by fitting. It can be seen that $\mathrm{CPE}_{1}$ and $R_{p 1}$ remain stable over the first $48 \mathrm{~h}$ after immersion and show 

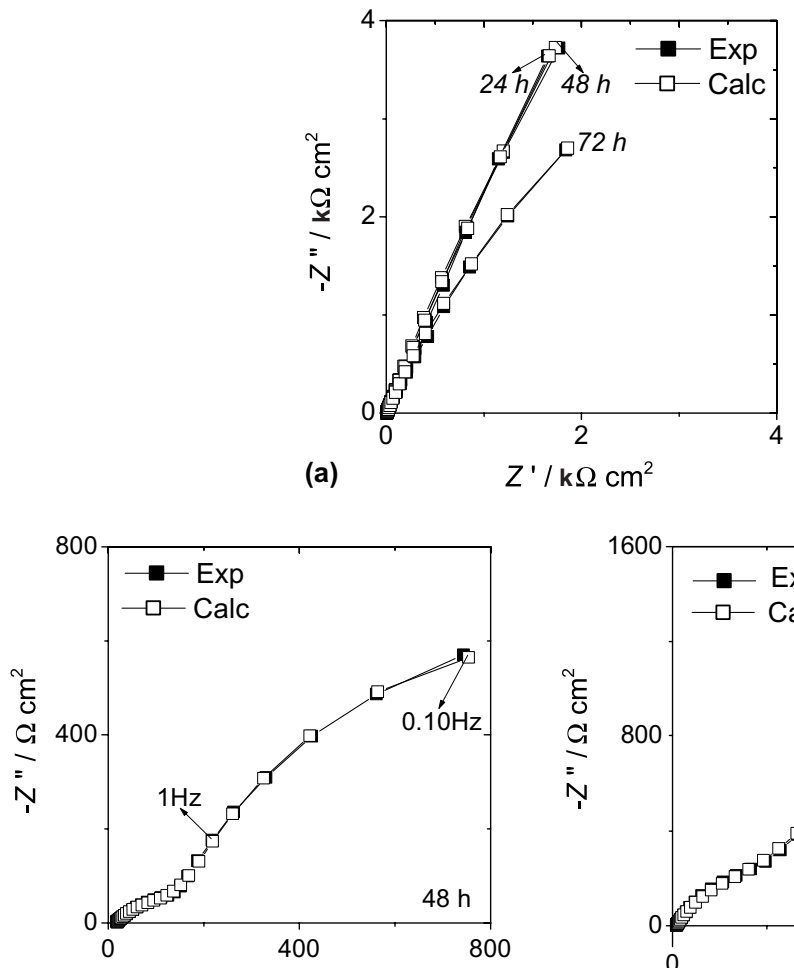

(b)

$Z^{\prime} / \Omega \mathrm{cm}^{2}$
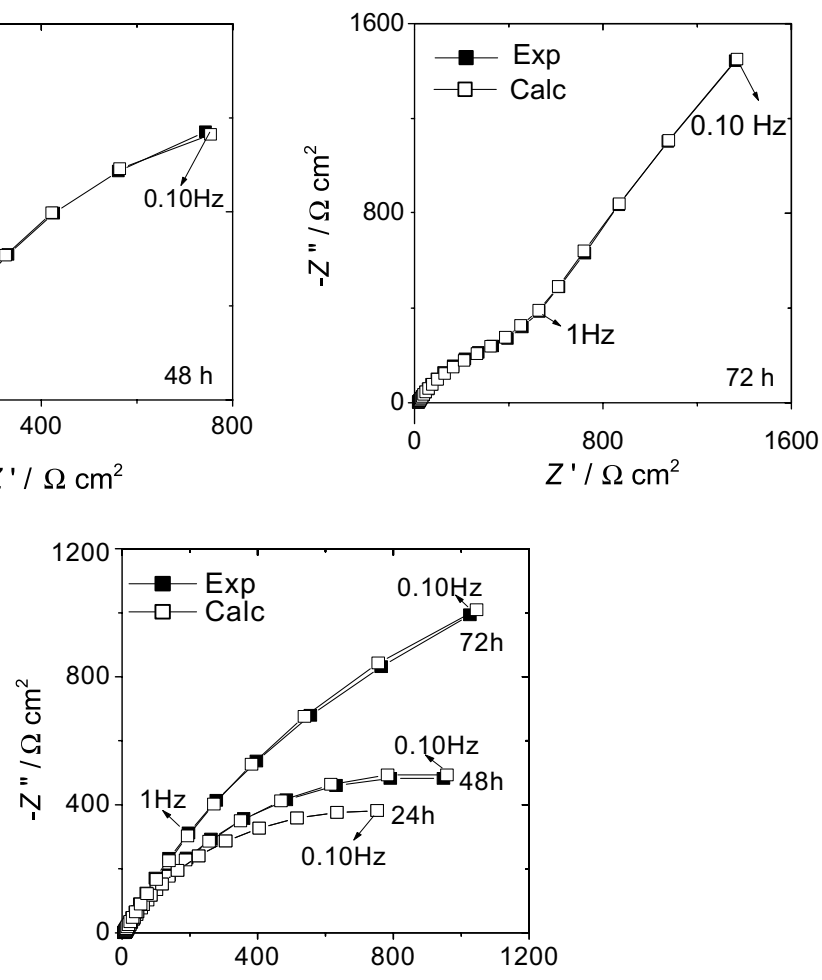

(c)

$Z^{\prime} / \Omega \mathrm{cm}^{2}$

Fig. 3. Complex plane impedance plots after 24,48 and $72 \mathrm{~h}$ immersion in $0.9 \% \mathrm{NaCl}$ at open circuit potential for (a) $\gamma_{1}-\mathrm{Ag}_{2} \mathrm{Hg}_{3}$, (b) $\mathrm{Ag}-\mathrm{Cu}$ eutectic, (c) $\gamma-\mathrm{Ag}_{3}-\mathrm{Sn}$.

a decrease after $72 \mathrm{~h}$ exposure. The values of the capacity of $\sim 0.3 \mathrm{mF} \mathrm{cm}^{-2}$ may be due to the enhanced microporosity and thence surface area in contact with solution. $R_{p 1}$ is of the order of $10^{4} \Omega$ and decreases by a factor of 2 after $72 \mathrm{~h}$ immersion. This 
Table 1

Fitting of impedance spectra for $\gamma_{1}-\mathrm{Ag}_{2} \mathrm{Hg}_{3}, \mathrm{Ag}-\mathrm{Cu}$ eutectic and $\gamma-\mathrm{Ag}_{3} \mathrm{Sn}$

\begin{tabular}{lllllllll}
\hline & $\begin{array}{l}\text { Immersion } \\
\text { time } / \mathrm{h}\end{array}$ & $R_{\Omega} / \Omega \mathrm{cm}^{2}$ & $R_{p 1} / \mathrm{k} \Omega \mathrm{cm}^{2}$ & $C_{1} / \mathrm{mF} \mathrm{cm}^{-2}$ & $\alpha_{1}$ & $R_{p 2} /{\mathrm{k} \Omega \mathrm{cm}^{2}}^{2}$ & $C_{2} / \mathrm{mF} \mathrm{cm}^{-2}$ & $\alpha_{2}$ \\
\hline$\gamma_{1}-\mathrm{Ag}_{2} \mathrm{Hg}_{3}$ & 24 & 7.94 & 26.0 & 0.33 & $0.78-$ & - & - \\
& 48 & 7.50 & 26.9 & 0.32 & $0.77-$ & - & - \\
& 72 & 7.58 & 11.9 & 0.38 & $0.76-$ & - & - \\
$\mathrm{Ag}-\mathrm{Cu}$ & 24 & 8.90 & 0.052 & 4.45 & 0.57 & 1.03 & 4.52 & 0.81 \\
& 48 & 18.0 & 0.147 & 0.40 & 0.56 & 1.62 & 1.28 & 0.80 \\
& 72 & 15.7 & 0.484 & 0.21 & 0.65 & 6.98 & 0.70 & 0.79 \\
$\gamma-\mathrm{Ag}_{3}-\mathrm{Sn}$ & 24 & 9.4 & 1.2 & 0.75 & $0.69-$ & & - \\
& 48 & 7.8 & 1.7 & 0.73 & $0.66-$ & - & - \\
& 72 & 6.6 & 4.0 & 0.67 & $0.70-$ & - & - \\
\hline
\end{tabular}

See Fig. 4 for meaning of symbols.

suggests that the passive oxide film initially formed on the surface can be attacked by ions from solution leading to a decrease in the corrosion resistance with time.

\subsubsection{The silver-copper eutectic phase}

For the $\mathrm{Ag}-\mathrm{Cu}$ eutectic phase, two semicircles appear in the complex plane plots at 48 and $72 \mathrm{~h}$ immersion as seen in Fig. 3b. Attempts to model this by two $R C$ terms in parallel, which would correspond to attacked and non-attacked surface areas, were not successful. However, it was possible to do so by using two $R(\mathrm{CPE})$ elements in series with the cell resistance, $R_{\Omega}$, as shown in Fig. $4 \mathrm{~b}$. The non-ideal capacitances

(a)
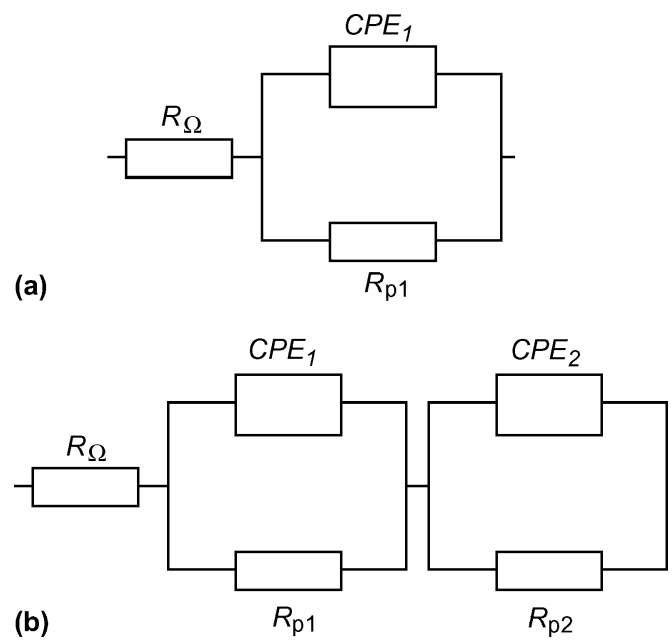

Fig. 4. Equivalent electrical circuits used for fitting of impedance spectra. (a) Circuit for $\gamma_{1}-\mathrm{Ag}_{2} \mathrm{Hg}_{3}$ and $\gamma-\mathrm{Ag}_{3}-\mathrm{Sn}$ (b) circuit for $\mathrm{Ag}-\mathrm{Cu}$ eutectic. 
$C$ are modelled by $\mathrm{CPE}_{1}$ and $\mathrm{CPE}_{2}$, can be correlated with metallic corrosion and with processes caused by the presence of corrosion products, i.e. oxide film, respectively.

Corrosion products can block the access of electrochemically active species to the electrode surface, restricting ion diffusion to the surface and thus reducing the overall corrosion reaction rate [10], which can explain the increase in $R_{p 2}$ with increasing immersion time, see Table 1 . Although much smaller, $R_{p 1}$ also increases with immersion time as more of the surface becomes covered by oxide.

\subsubsection{The silver-tin phase}

The spectra for $\gamma-\mathrm{Ag}_{3} \mathrm{Sn}$, Fig. 3c, can be interpreted based on a model with the circuit elements representing only the electrochemical properties of the oxide film, using a parallel combination of a resistance $R_{p}$ and a constant phase element substituting the capacitance of the interfacial region, as in Fig. 4a. The slight decrease of the CPE with time may correspond to a slow growth of the oxide film, indicating a long-term stability of the thin passive film in solution. This is also demonstrated by the slight increase of $R_{p 1}$ with exposure time, the values of which are low in agreement with this explanation, Table 1.

\subsection{Electrochemical noise analysis}

In a noise experiment the potential and current are measured at a fixed rate for a chosen time interval. Other parameters obtained are the mean potential, $E_{\text {coup }}$, which is the potential of the coupled electrodes vs. a stable reference electrode (here SCE), and $I_{\text {coup }}$ which is the mean coupling current flowing between the two electrodes, measured by a zero resistance ammeter (ZRA).

Potential and current noise time records were first analyzed statistically by calculating the mean and the standard deviation for each data set. The noise resistance $R_{\mathrm{n}}$ is the ratio of standard deviation of potential $\sigma[V(t)]$ divided by the standard deviation of current $\sigma[I(t)]$. The experimental data were then transformed from the time domain into the frequency domain by FFT. Spectral noise plots were then obtained from which the spectral noise resistance, $R_{\mathrm{sn}}^{0}$, was determined, defined as $[11,12]$ :

$$
R_{\mathrm{sn}}^{0}=\lim _{f \rightarrow 0}\left(R_{\mathrm{sn}}(f)\right)
$$

Potential and current PSD plots have the general frequency dependence:

$$
\begin{aligned}
& \log V_{\mathrm{PSD}}=A_{V}+S_{V} \log f \\
& \log I_{\mathrm{PSD}}=A_{I}+S_{I} \log f
\end{aligned}
$$

where $S_{V}$ and $S_{I}$ are the slopes of the potential and current spectral noise plots, respectively; while for the spectral noise resistance plot:

$$
\log R_{\mathrm{sn}}=A_{R \mathrm{sn}}+S_{R \mathrm{sn}} \log f
$$


Since $R_{\mathrm{sn}}(f)=\left|V_{\mathrm{PSD}} / I_{\mathrm{PSD}}\right|^{1 / 2}$, it follows that:

$$
S_{R \mathrm{sn}}=0.5\left(S_{V}-S_{I}\right)=S_{Z}
$$

where $S_{R \text { sn }}$ and $S_{Z}$ are the slopes of the spectral noise plot and of the Bode plot.

Typical power spectral noise plots for the three phases after $72 \mathrm{~h}$ immersion are shown in Fig. 5. Values of all the important parameters can be found in Table 2 for 24,48 and $72 \mathrm{~h}$ immersion.

The plots of $R_{\mathrm{sn}}$ vs. $\log f$ were compared to impedance spectra obtained under similar conditions in the same way as described in $[11,12]$, see also Fig. 5.

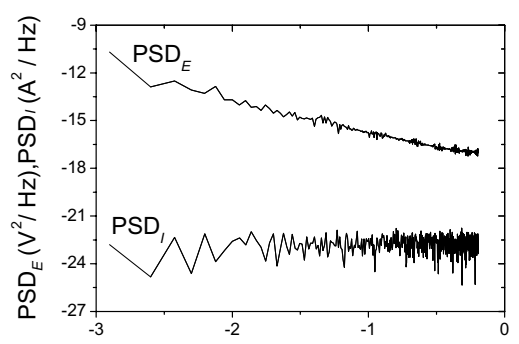

(a)

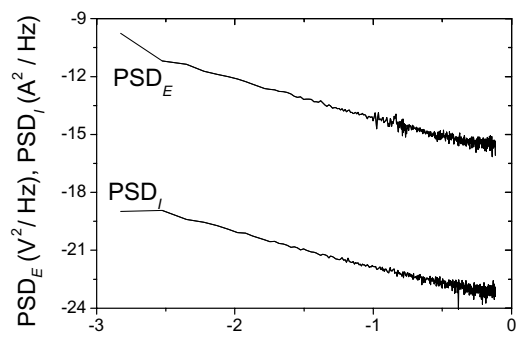

(b) $\quad \lg f / \mathrm{Hz}$

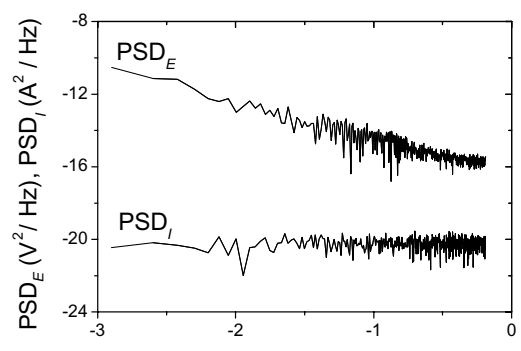

(c)

$\lg f / \mathrm{Hz}$
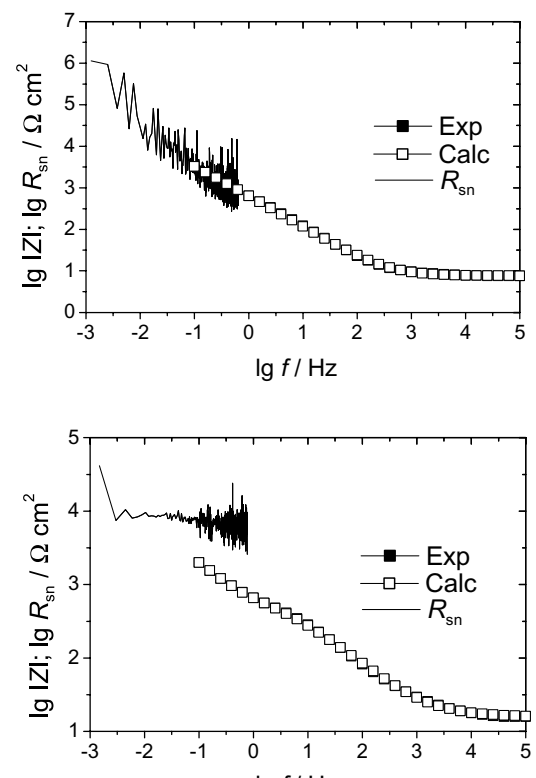

$\lg f / \mathrm{Hz}$

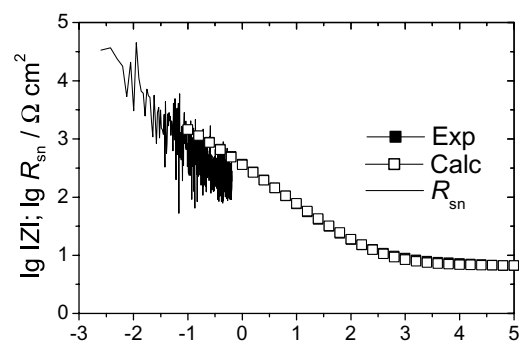

$\lg f / \mathrm{Hz}$

Fig. 5. Electrochemical noise analysis for samples of (a) $\gamma_{1}-\mathrm{Ag}_{2} \mathrm{Hg}_{3}$, (b) $\mathrm{Ag}-\mathrm{Cu}$ eutectic, (c) $\gamma-\mathrm{Ag}_{3}-\mathrm{Sn}$, immersed in $0.9 \% \mathrm{NaCl}$ for $72 \mathrm{~h}$, showing potential and current PSD plots and comparison of resulting spectral noise plots $\left[R_{\mathrm{sn}}(f)\right]$ with impedance spectra $(|Z|$ vs. $f)$. 
Table 2

Electrochemical noise data analysis for $\gamma_{1}-\mathrm{Ag}_{2} \mathrm{Hg}_{3}, \mathrm{Ag}-\mathrm{Cu}$ eutectic and $\gamma-\mathrm{Ag}_{3} \mathrm{Sn}$ after 24,48 and $72 \mathrm{~h}$ of immersion in $0.9 \% \mathrm{NaCl}$

\begin{tabular}{|c|c|c|c|c|c|c|c|c|c|c|c|c|}
\hline & $\begin{array}{l}\text { Immersion } \\
\text { time/h }\end{array}$ & $\begin{array}{l}E_{\text {coup }} / \\
\text { V vs. SCE }\end{array}$ & $\begin{array}{l}I_{\text {coup }} / \\
\mathrm{Acm}^{-2}\end{array}$ & $\sigma[V(t)]$ & $\sigma[I(t)]$ & $\begin{array}{l}R_{\mathrm{n}} / \\
\mathrm{k} \Omega \mathrm{cm}^{2}\end{array}$ & $\begin{array}{l}R_{\mathrm{s} \mathrm{I}}^{0} \\
\mathrm{k} \Omega \mathrm{cm}^{2}\end{array}$ & $S_{V}$ & $S_{I}$ & $S_{R \mathrm{sn}}$ & $\begin{array}{l}\left|Z_{1}\right|_{f \rightarrow 0^{0}}{ } \Omega^{2} \mathrm{~cm}^{2}\end{array}$ & $\begin{array}{l}\left|Z_{2}\right|_{f \rightarrow 0} d^{\prime} \\
\mathrm{k} \Omega \mathrm{cm}^{2}\end{array}$ \\
\hline \multirow[t]{3}{*}{$\gamma_{1}-\mathrm{Ag}_{2} \mathrm{Hg}_{3}$} & 24 & 0.047 & $2.4 \times 10^{-7}$ & $2.6 \times 10^{-5}$ & $1.9 \times 10^{-9}$ & 14 & 7 & -1.84 & -1.74 & -0.05 & 26 & - \\
\hline & 48 & 0.068 & $2.8 \times 10^{-8}$ & $7.1 \times 10^{-5}$ & $1.8 \times 10^{-9}$ & 40 & 140 & -1.79 & 0.08 & -0.91 & 27 & - \\
\hline & 72 & 0.073 & $1.9 \times 10^{-8}$ & $4.7 \times 10^{-5}$ & $2.7 \times 10^{-9}$ & 17 & 320 & -1.85 & 0.02 & -0.89 & 12 & - \\
\hline \multirow[t]{3}{*}{$\mathrm{Ag}-\mathrm{Cu}$} & 24 & -0.075 & $1.8 \times 10^{-6}$ & $3.6 \times 10^{-5}$ & $9.5 \times 10^{-7}$ & 37.1 & 3.7 & -1.80 & -0.27 & -0.760 & 0.052 & 1.0 \\
\hline & 48 & -0.047 & $5.6 \times 10^{-7}$ & $9.3 \times 10^{-5}$ & $3.3 \times 10^{-7}$ & 280 & 8.4 & -1.79 & 0.167 & -0.953 & 0.15 & 1.6 \\
\hline & 72 & -0.038 & $1.7 \times 10^{-7}$ & $9.9 \times 10^{-5}$ & $1.1 \times 10^{-8}$ & 9401 & 12 & -1.81 & -1.60 & -0.084 & 0.48 & 7.0 \\
\hline \multirow[t]{3}{*}{$\gamma-\mathrm{Ag}_{3}-\mathrm{Sn}$} & 24 & 0.055 & $1.3 \times 10^{-7}$ & $1.3 \times 10^{-4}$ & $1.1 \times 10^{-8}$ & 12 & 37 & -1.89 & -0.399 & -0.726 & 1.2 & - \\
\hline & 48 & 0.051 & $1.3 \times 10^{-7}$ & $8.2 \times 10^{-5}$ & $1.6 \times 10^{-8}$ & 5 & 39 & -1.94 & -0.209 & -0.853 & 1.7 & - \\
\hline & 72 & 0.046 & $1.7 \times 10^{-8}$ & $4.4 \times 10^{-5}$ & $4.4 \times 10^{-8}$ & 1 & 20 & -1.79 & -0.010 & -0.905 & 4.0 & - \\
\hline
\end{tabular}




\subsubsection{The silver-mercury phase}

Excellent agreement was found when comparing the spectral signal resistance plot with the impedance spectrum (Bode), for the same immersion time, within the common frequency band analyzed for both kinds of plot, Fig. 5a. This shows that the same results can be obtained by applying a sinusoidal signal, or using the natural occurrence of potential or current variations $[11,12]$. In this case the impedance spectrum has only one time constant, which make the comparison relatively easy.

\subsubsection{The silver-copper eutectic}

An equivalent electrical circuit was used to determine $|Z|_{f \rightarrow 0}$, with the option of considering the addition $|Z|_{f \rightarrow 0}=R_{p 1}+R_{p 2}$ of both capacitive contributions, at high and low frequencies of the impedance spectrum. The other option was to compare the values of $R_{p 1}$ and $R_{p 2}$ found with EIS to those of $R_{\mathrm{n}}(t)$ and $R_{\mathrm{sn}}^{0}\left(f_{\min }\right)$, respectively. The values of $R_{p 1}$ are significantly higher than their corresponding $R_{\mathrm{n}}$ (see Table 2), however they vary according to the immersion time within the same order of magnitude. Furthermore, good agreement is observed between $R_{p 2}$ and $R_{\mathrm{sn}}$ which may be taken into consideration, since $R_{\mathrm{sn}}$ is calculated at very low frequencies, where the $R_{p 2}$ contribution is clearly evident. The largest deviations occur after $72 \mathrm{~h}$ immersion, which is the time shown in Fig. 5b-within experimental error, the agreement is very good after 24 and $48 \mathrm{~h}$ immersion, suggesting that the second element becomes ore important after significant corrosion has occurred. From Table 1, a large difference between 24 and $48 \mathrm{~h}$ immersion on the one hand, and $72 \mathrm{~h}$ on the other is evident.

\subsubsection{The silver-tin phase}

Good agreement with Eq. (4) was observed in the $S_{V}, S_{I}$ and $S_{R \text { sn }}$ values obtained from the PSD plots, Fig. 5c.

While $\sigma[V(t)]$ remains generally constant throughout the $72 \mathrm{~h}$ immersion interval, $\sigma[I(t)]$ shows a slight increase. As a result, $R_{\mathrm{n}}$ decreases with time, Table 2 . The values found for $R_{\mathrm{n}}, R_{\mathrm{sn}}^{0}$ and $|Z|_{f \rightarrow 0}$ remained between $10^{3}$ and $10^{4} \Omega \mathrm{cm}^{2}$, Table 2 , although they were obtained by applying different techniques. It was observed that $R_{\mathrm{n}}$ was always lower than $R_{\mathrm{sn}}^{0}$ which may have occurred due to the different analysis methods, since $R_{\mathrm{sn}}^{0}$ was obtained from extrapolation at $f \rightarrow 0$ or being the average over the last 10 points.

\subsection{Comparative remarks}

Polarization curves show corrosion potentials most positive for $\gamma_{1}-\mathrm{Ag}_{2} \mathrm{Hg}_{3}$, followed by $\mathrm{Ag}-\mathrm{Cu}$ and $\gamma-\mathrm{Ag}_{3} \mathrm{Sn}$ reflecting the order of corrosion resistance after 10 min immersion as measured by the corrosion currents.

The values of $R_{p}$ obtained by impedance and calculated by electric equivalent circuits are in good agreement with $R_{\mathrm{sn}}^{0}$ calculated by electrochemical noise for $\gamma_{1}-\mathrm{Ag}_{2} \mathrm{Hg}_{3}, \gamma-\mathrm{Ag}_{3} \mathrm{Sn}$ and $\mathrm{Ag}-\mathrm{Cu}$.

Comparing all the single-phase alloys, more complex impedance spectra are obtained for $\mathrm{Ag}-\mathrm{Cu}$, with an enhanced distortion of the low frequency of the impedance curves which may be interpreted as involving non-uniform diffusion either in 
the bulk or at an interface. The relatively high $\mathrm{CPE}_{1}$ value for $\gamma_{1}-\mathrm{Ag}_{2} \mathrm{Hg}_{3}$ may indicate the enhanced porous feature in the surface: $R_{p}$ is in the order of several tens of $\mathrm{k} \Omega \mathrm{cm}^{2}$ and decreases after $72 \mathrm{~h}$ immersion. The slight decrease of the $\mathrm{CPE}_{1}$ for $\gamma-\mathrm{Ag}_{3} \mathrm{Sn}$ may correspond to a slow growth of the oxide film, indicating a long-term stability of the thin passive film in solution.

The phase which undergoes corrosion most easily- $\mathrm{Ag}-\mathrm{Cu}$ eutectic-does not have a significant role, and should not if the dental amalgam is properly prepared and the reactions shown in the introductory section go to completion. These results show that the phase boundaries are also of importance in describing the corrosion behaviour. Whereas at short immersion times up to $24 \mathrm{~h}$, the contributions of the $\gamma_{1}-\mathrm{Ag}_{2} \mathrm{Hg}_{3}$ and $\gamma-\mathrm{Ag}_{3} \mathrm{Sn}$ phases can be clearly seen [4], for longer periods of immersion the corrosion rate becomes very low in the medium tested, also suggesting almost complete coverage of the parts of the surface susceptible to dissolution by oxide film.

The most important results obtained from the analysis of the electrochemical noise data are $R_{\mathrm{n}}, R_{\mathrm{sn}}^{0}$ and the PSD slopes, which give information concerning the different corrosion aspects. Similar values of order of magnitude $10^{3}$ and $10^{4}$ $\Omega \mathrm{cm}^{2}$, were found for $R_{\mathrm{n}}$ and $R_{\mathrm{sn}}^{0}$ despite the fact that those results were determined by different analysis methods. This reflects a relatively uniform surface structure and the absence of significantly important localized phenomena in the corrosion process. The increase of $R_{\mathrm{n}}$ and $R_{\mathrm{sn}}^{0}$ with time, agree with the variations of $|Z|_{f \rightarrow 0}$ with time obtained by EIS, as was the case for $\mathrm{Ag}-\mathrm{Cu}$.

\section{Conclusions}

The combination of various electrochemical techniques, particularly the non-stationary electrochemical impedance and noise analysis, has contributed to the understanding of the corrosion of individual dental amalgam phases under in vitro conditions.

The surface analysis for the studied alloys reveals rough materials, which is confirmed in impedance spectra analysis. The electrochemical behaviour of these materials in $0.9 \% \mathrm{NaCl}$ is characteristic of passive systems; the corrosion mechanism involves the formation of corrosion products which protect the metallic surface at low potentials.

\section{Acknowledgements} Brazil.

H. A. A. acknowledges a doctoral grant from FAPESP, process no. 97/12217-0,

\section{References}

[1] R.G. Craig, Restorative Dental Materials, Mosby, St. Louis, USA, 1985.

[2] B. Westerhoff, M. Darwish, R. Holze, J. Appl. Electrochem. 22 (1992) 1142-1146. 
[3] B. Westerhoff, M. Darwish, R. Holze, J. Oral Rehabil. 22 (1995) 121-125.

[4] H.A. Acciari, E.N. Codaro, A.C. Guastaldi, Mater. Lett. 36 (1998) 148-151.

[5] H.A. Acciari, A.C. Guastaldi, C.M.A. Brett, Electrochim. Acta 46 (2001) 3887-3893.

[6] L. Lemaitre, M. Moors, P. Van Peteghem, J. Oral Rehabil. 16 (1989) 537-541.

[7] American Dental Association Council on Dental Materials and Devices. Specification no. 1 for alloy for dental amalgam, J. Amer. Dent. Ass. vol. 95, 1977, p. 1171.

[8] N.K. Sarkar, The electrochemical behavior of dental amalgams and their component phases, Thesis (Doctor of Philosophy) - Northwestern University. Evanston, Illinois, 1993.

[9] P.L. Bonora, F. Deflorian, L. Fedrizzi, Electrochim. Acta 41 (1996) 1073-1082.

[10] C. Gabrielli, Identification of electrochemical processes by frequency response analysis, Solartron Instruments, Technical Report Number 004/83, 1983.

[11] F. Mansfeld, C.C. Lee, G. Zhang, Electrochim. Acta 43 (1998) 435-438.

[12] F. Mansfeld, L.T. Han, C.C. Lee, C. Chen, G. Zhang, H. Xiao, Corros. Sci. 39 (1997) 255-279. 